Communications in Physics, Vol. 30, No. 4 (2020), pp. 331-343

DOI:10.15625/0868-3166/30/4/14888

\title{
FEATURE PROPERTIES OF PHOTONIC CRYSTAL FIBER WITH HOLLOW CORE FILLED BY NITROBENZENE
}

\author{
TRAN QUOC VU ${ }^{1}$, CHU THI GIA TRANG ${ }^{2}$, LE VAN MINH $^{2}$, NGUYEN THI THUY ${ }^{3}$, \\ NGUYEN THI HONG PHUONG ${ }^{4}$, DOAN QUOC KHOA ${ }^{5}$, DINH XUAN KHOA ${ }^{6}$, \\ LE XUAN BAO ${ }^{6}$, VO THI MINH NGOC ${ }^{7}$ AND CHU VAN LANH ${ }^{6, \dagger}$ \\ ${ }^{1}$ Thu Khoa Nghia High School for The Gifted, Chau Doc city, An Giang, Vietnam \\ ${ }^{2}$ School of Engieering and Technology, Vinh University, 182 Le Duan, Vinh city, Vietnam \\ ${ }^{3}$ Hue University of Education, Hue University, 34 Le Loi Street, Hue City, Vietnam \\ ${ }^{4}$ Nguyen Chi Thanh High School, Hoa Thanh district, Tay Ninh province, Vietnam \\ ${ }^{5}$ Quang Tri Teacher Training College, Dong Ha, Quang Tri province, Vietnam \\ ${ }^{6}$ School of Natural Science Education, Vinh University, 182 Le Duan, Vinh City, Vietnam \\ ${ }^{7}$ Huynh Thuc Khang High School, La Grai district, Gia Lai province, Vietnam \\ ${ }^{\dagger} E$-mail: chuvanlanh@vinhuni.edu.vn
}

Received 12 March 2020

Accepted for publication 14 May 2020

Published 20 October 2020

\begin{abstract}
In this paper, a photonic crystal fiber $(P C F)$ with core infiltrated with Nitrobenzene is proposed and investigated. Its feature properties such as the effective refractive index, effective mode area, chromatic dispersion, and confinement loss have been numerically simulated. The obtained results show that characteristic quantities of $P C F$ with core infiltrated with Nitrobenzene $(P C F-N)$ have some advantages in comparison to PCF with core infiltrated with Toluene (PCF-T) at $1.55 \mu \mathrm{m}$ wavelength. For the purpose of supercontinuum generation, two optimal structures with lattice constants, $\Lambda=2.0 \mu \mathrm{m}$ and $\Lambda=2.5 \mu \mathrm{m}$, with filling factors $d / \Lambda=0.3$ are identified.
\end{abstract}

Keywords: photonic crystal fibers; nonlinear optical materials; supercontinuum generation.

Classification numbers: 42.81.-i; 42.81.Wg.

\section{INTRODUCTION}

The first PCF was proposed and investigated by Russell in 1996 [1]. Since then it has attracted the special attention of scientists on the world, consequently, the different kinds in the configuration of PCF have been improved for the rich applications due to advantages in comparison to conventional optical fibers [2-8]. The main properties of PCF influencing on the application C2020 Vietnam Academy of Science and Technology 
fields are the effective refractive index, effective mode area, dispersion, and confinement loss. Up to now, there is a lot of works, theoretical as well as experimental, that investigated the effective refractive index [9-11], guiding mechanism of light in photonic crystal fiber [12], effective mode area [13,14], dispersion [15-20] and confinement loss [21-23] and improved them by infiltration on air-holes with liquids for specific applications. In recent years, PCFs with air holes have been infiltrated with liquids having different refractive index and higher nonlinearity on the cladding or the core of photonic crystals fiber as designing a dual-core PCF coupler [24], D-glucose sensor using PCF [25], dispersion engineering of photonic crystal fibers by means of fluidic infiltration [26], liquid-filled simplified hollow-core PCF [27]. Infiltration with liquids on the core the PCF has a high loss limitation, but it has an advantage that the nonlinearity is higher, since the fundamental mode is very well confined in the PCF core [28]. This property makes PCF to be the good medium for supercontinuum generation [29-31]. The solid-core PCFs and liquid-filled hollow-core PCFs differ in their structure, which is at the center of the fiber core for solid core is silica and for hollow core is liquid. This leads to the same light transmission in PCF as in solid-core PCFs, i.e., the principle of total reflection is still followed [5].

It has already been demonstrated that a broad supercontinuum generation is possible using liquids, such as carbon tetrachloride [32,33], toluene [32,33], Carbon disulfide [32-34]. The fact that at $1.064 \mu \mathrm{m}$ Nitrobenzene has $\mathrm{n}_{2}=685.10^{-20} \mathrm{~m}^{2} / \mathrm{W}$ while Toluene has $\mathrm{n}_{2}=160.10^{-20} \mathrm{~m}^{2} / \mathrm{W}[32$, 33] (i.e., $n_{2}$ of Nitrobenzene is about 5 times larger than $n_{2}$ of Toluene) gives us an idea to propose PCF with hollow-core infiltrated with Nitrobenzene and hope this would improve the efficiency of supercontinuum generation.

The PCF with hollow-core infiltrated with Toluene (PCF-T) has been proposed and investigated in detail [28]. Two optimal structures with the same lattice constant $\Lambda=2 \mu \mathrm{m}$ but diferent filling factors $d / \Lambda=0.3$ and 0.35 are analyzed and discussed for supercontinuum generation. Because Toluene has strong light absorption and not large enough nonlinear refractive index there are some undesired limitations in PCF infiltrated Toluene such as high confinement loss of $0.4 \mathrm{~dB} / \mathrm{cm}$ and quite large effective mode area.

To overcome the mentioned limitations, in this paper, we proposed to use Nitrobenzene as infiltrating liquid into the hollow core of photonic crystal fiber. All of its feature properties have been simulated and discussed in comparison to those of PCF with core infiltrated with Toluene.

\section{DESIGN AND THEORY}

The target structures of PCF in this study are similar to those presented in previous work [28], except for the infiltrating liquid Toluene replaced by Nitrobenzene. Its geometrical structure is simulated and presented in Fig. 1.

The refractive index of Nitrobenzene [35] and fused silica given by Sellmeier's equation as follows [36]:

$$
n(\lambda)=\sqrt{A_{0}+\frac{A_{1} \lambda^{2}}{\lambda^{2}-B_{1}}+\frac{A_{2} \lambda^{2}}{\lambda^{2}-B_{2}}+\frac{A_{3} \lambda^{2}}{\lambda^{2}-B_{3}}},
$$

where $\lambda(\mu \mathrm{m})$ is the wavelength, $A_{0,1,2,3}$, and $B_{1,2,3}$ are the Sellmeier coefficients of Nitrobenzene and fused silica given in Table 1. Using Eq. (1) and Sellmeier coefficients, the real refractive index- wavelength characteristics are plotted in Fig. 2. 


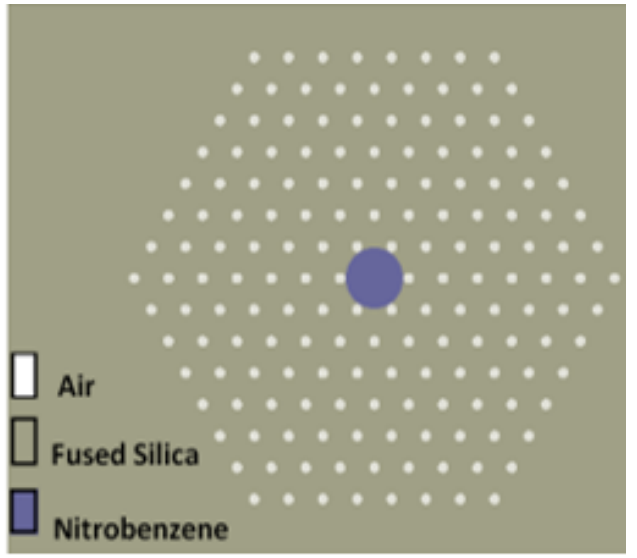

Fig. 1. The geometrical structure of PCF-N.

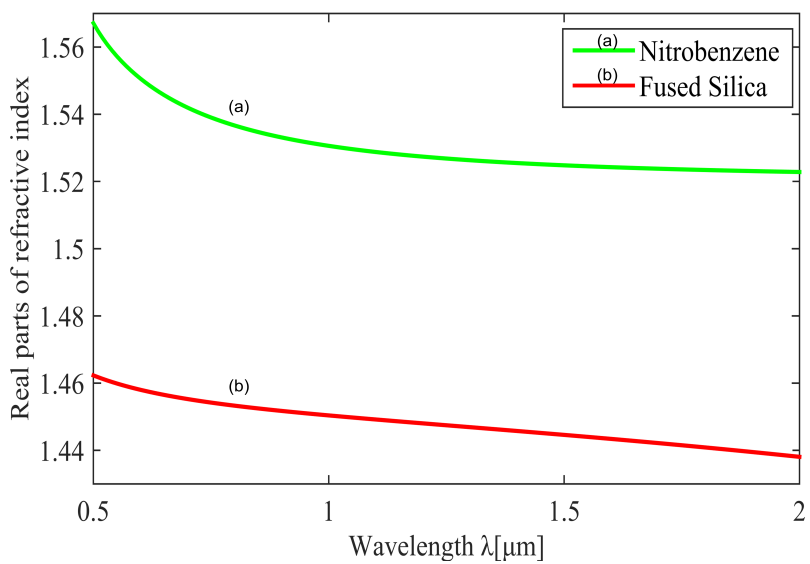

Fig. 2. Real parts of refractive index of (a) Nitrobenzene and (b) Fused Silica.

Table 1. Sellmeier coefficients of Nitrobenzene and Fused Silica.

\begin{tabular}{|c|c|c|}
\hline Sellmeier coefficients & Nitrobenzene [35] & Fused Silica [36] \\
\hline $\mathrm{A}_{0}$ & 1 & 1 \\
\hline $\mathrm{A}_{1}$ & 1.30628 & 0.6694226 \\
\hline $\mathrm{A}_{2}$ & 0.00502 & 0.4345839 \\
\hline $\mathrm{A}_{3}$ & 0 & 0.8716947 \\
\hline $\mathrm{B}_{1}$ & $0.02268 \mu \mathrm{m}^{2}$ & $4.4801 \times 10^{-3} \mu \mathrm{m}^{2}$ \\
\hline $\mathrm{B}_{2}$ & $0.18487 \mu \mathrm{m}^{2}$ & $1.3285 \times 10^{-2} \mu \mathrm{m}^{2}$ \\
\hline $\mathrm{B}_{3}$ & 0 & $95.341482 \mu \mathrm{m}^{2}$ \\
\hline
\end{tabular}

Differently from that of convenient fibers, in the PCF there are four important main parameters influencing the propagation of light which are the effective refractive index $n_{\text {eff }}$, effective mode area $A_{\text {eff }}$, dispersion $\mathrm{D}$ and confinement loss $L_{c}$. The effective refractive index $n_{\text {eff }}$ is related to phase constant $\beta$ and wavenumber $k_{0}=2 \pi / \lambda$ as follows [5]:

$$
n_{\text {eff }}=\frac{\beta\left(\lambda, n_{m}(\lambda)\right)}{k_{0}} .
$$

The relation between the effective area $A_{\text {eff }}$ and the electric field amplitude $E(x, y)$ in the core - PCF $[5,13,14]$ is given by:

$$
A_{e f f}=\left(\int_{-\infty}^{\infty} \int_{-\infty}^{\infty}|E(x, y)|^{2} d x d y\right)^{2} / \int_{-\infty}^{\infty} \int_{-\infty}^{\infty}|E(x, y)|^{4} d x d y .
$$


FEATURE PROPERTIES OF PHOTONIC CRYSTAL FIBER WITH HOLLOW CORE FILLED ...

The dispersion $D$ describing the broadening or spreading of light pulse inside the PCF is given as [14-18]:

$$
D=-\frac{\lambda}{c} \frac{d^{2}}{d \lambda^{2}} \operatorname{Re}\left[n_{e f f}\right]
$$

where $d^{2} / d \lambda^{2}$ is quadratic derivative with the wavelength, $\operatorname{Re}\left[\mathrm{n}_{e f f}\right]$ is the real part of $n_{\text {eff }}$, and $c$ is the speed of light in vacuum.

The confinement loss, $L_{c}$, a very important quantity for PCF due to the finite number of air holes designed in the cross-section [21,22] is defined by equation [23]:

$$
L_{c}=0.08686 k_{0} \operatorname{Im}\left[n_{e f f}\right](d B / \mathrm{cm}),
$$

where $\operatorname{Im}\left[n_{\text {eff }}\right]$ is the imaginary part of the $n_{\text {eff }}$ and $k_{0}=\frac{2 \pi}{\lambda}$ is the propagation constant in free space.

All of the above parameters depend on the structure of PCF [5] and determine the properties of PCF.

\section{RESULTS AND DISCUSSION}

\section{III.1. Effective refractive index}

Table 2. The values of the effective refractive index at $1.55 \mu \mathrm{m}$ wavelengths for lattice

\begin{tabular}{|c|c|c|c|c|c|}
\hline \multirow{2}{*}{$\lambda(\mu \mathrm{m})$} & \multirow{2}{*}{$d / \Lambda$} & \multicolumn{2}{|c|}{$\Lambda=2.0(\mu \mathrm{m})$} & \multicolumn{2}{|c|}{$\Lambda=2.5(\mu \mathrm{m})$} \\
\hline & & $\begin{array}{c}\quad n_{\text {eff }} \\
\text { Nitrobenzen }\end{array}$ & $\begin{array}{c}\quad n_{\text {eff }} \\
\text { Toluen [28] }\end{array}$ & $\begin{array}{c}\quad n_{\text {eff }} \\
\text { Nitrobenzen }\end{array}$ & $\begin{array}{c}\quad n_{\text {eff }} \\
\text { Toluen [28] }\end{array}$ \\
\hline \multirow{11}{*}{1.55} & 0.3 & 1.49663 & 1.45235 & 1.50546 & 1.46001 \\
\hline & 0.35 & 1.49471 & 1.45023 & 1.50420 & 1.45868 \\
\hline & 0.4 & 1.49254 & 1.44785 & 1.50271 & 1.45705 \\
\hline & 0.45 & 1.49029 & 1.44545 & 1.50123 & 1.45581 \\
\hline & 0.5 & 1.48778 & 1.44294 & 1.49960 & 1.45393 \\
\hline & 0.55 & 1.48507 & 1.44022 & 1.49789 & 1.45210 \\
\hline & 0.6 & 1.48203 & 1.43717 & 1.49577 & 1.45028 \\
\hline & 0.65 & 1.47880 & 1.43392 & 1.49352 & 1.44803 \\
\hline & 0.7 & 1.47510 & 1.43014 & 1.49112 & 1.44553 \\
\hline & 0.75 & 1.47107 & 1.42622 & 1.48824 & 1.44288 \\
\hline & 0.8 & 1.46645 & 1.42165 & 1.48518 & 1.43971 \\
\hline
\end{tabular}
constants $\Lambda=2.0 \mu \mathrm{m} ; \Lambda=2.5 \mu \mathrm{m}$ and filling factor $d / \Lambda$ varying from 0.3 to 0.8 . 

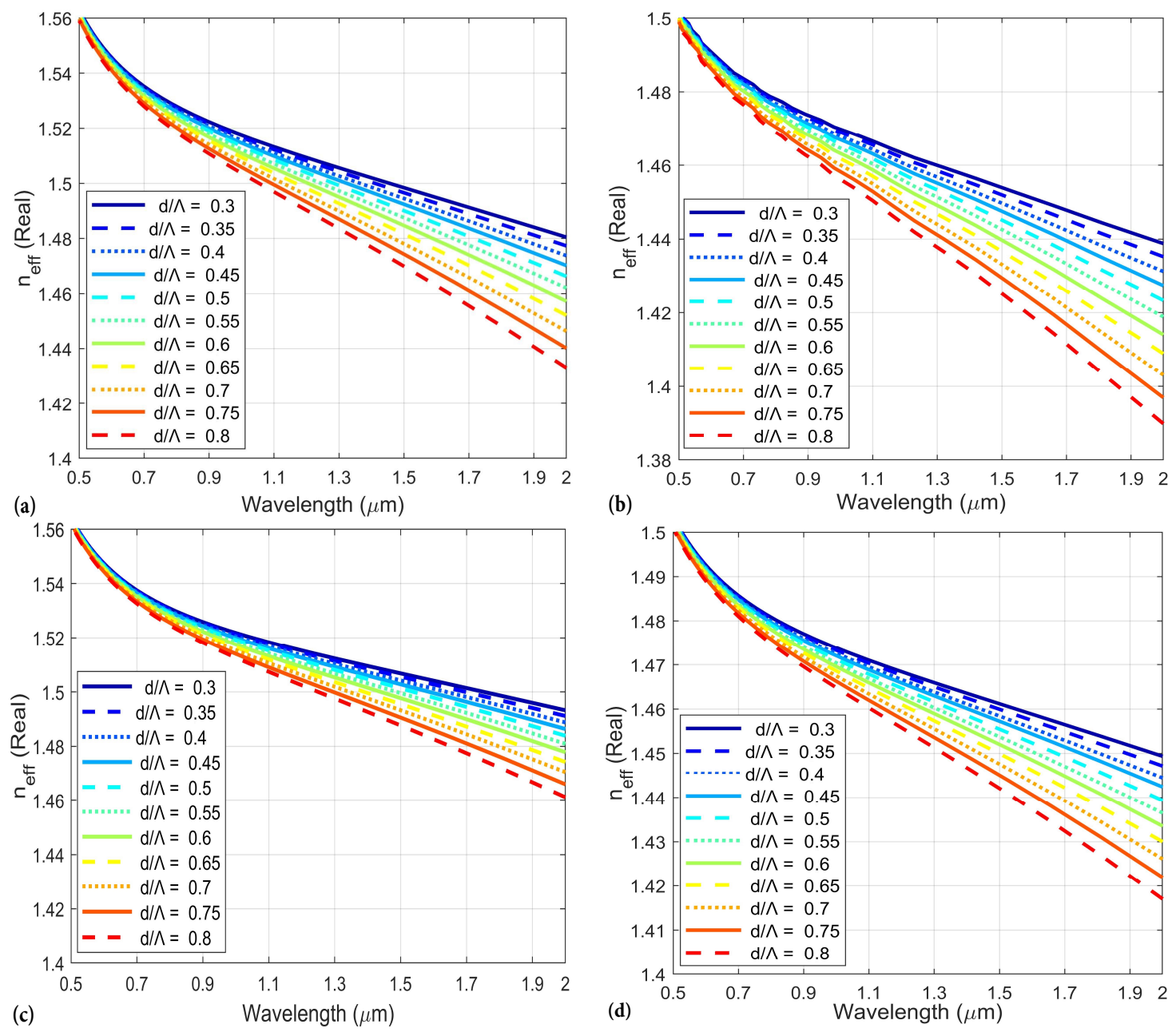

Fig. 3. $\operatorname{Re}\left[\mathrm{n}_{\text {eff }}\right]$ vs. $\lambda$ with filling factor $d / \Lambda$ varying from 0.3 to 0.8 and lattice pitch of $\Lambda=2.0 \mu \mathrm{m}$ \{a) Nitrobenzen, b) Toluen [28]\} and $\Lambda=2.5 \mu \mathrm{m}\{\mathrm{c})$ Nitrobenzen, d) Toluen [28]\}.

In Fig. 3, we presented the effective refractive index $n_{\text {eff }}$ of fundamental modes simulated for PCF-N having structures with lattice constants $\Lambda=2.0 \mu \mathrm{m}$ and $\Lambda=2.5 \mu \mathrm{m}$ and filling factor $d / \Lambda$ varies from 0.3 to 0.8 . The effective refractive index curves are similar to the results obtained for PCF with hollow core infiltrated with Toluene [28].

Since the lattice constants are unchanged, the appearance of curves of $\operatorname{Re}\left[n_{\text {eff }}\right]$ is seen to be similar for both cases of PCF-N and PCF-T [28], but their magnitudes at a given wavelength are clearly different, which are listed in Table 2, as an example for a wavelength of $1.55 \mu \mathrm{m}$. In all of simulated cases, the effective refractive index of PCF-N is greater than that of PCF-T. This phenomenon can be explained by the fact that the refractive index of Nitrobenzene is greater than that of Toluene, which is determined by different Sellmeier coefficients [37]. 


\section{III.2. Effective mode area}

In Fig. 4 there are the simulated effective mode area-wavelength characteristics. From the curves in Fig. 4, it can be seen that the effective mode area is almost proportional to the wavelength $\lambda$ and inversional to filling factor $d / \Lambda$. This is because the light is more strongly absorbed in large wavelengths range, and more losses when the filling factor increases, moreover the diameter of air-hole decreases, thus the diameter of liquid core increases. Comparing to that of PCF-T, the effective mode area of PCF-N is smaller because the nonlinear refractive index of Nitrobenzene is greater than the nonlinear refractive index of Toluene.
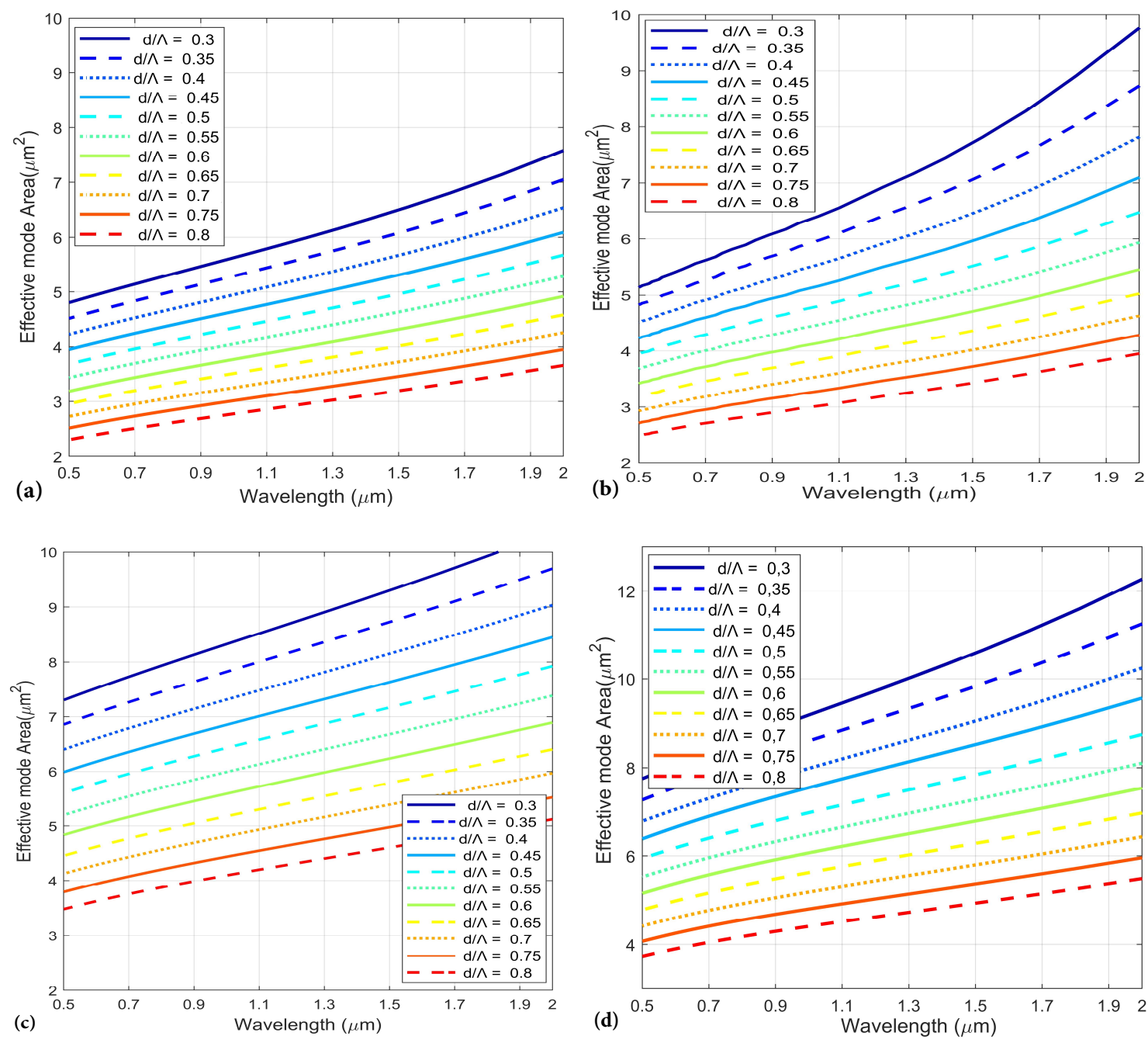

Fig. 4. $A_{\text {eff }}$ vs. $\lambda$ with filling factor $d / \Lambda$ varying from 0.3 to 0.8 and lattice constant $\Lambda=2.0 \mu \mathrm{m}$ \{a) Nitrobenzen, b) Toluen [28] $\}$ and $\Lambda=2.5 \mu \mathrm{m}\{$ c) Nitrobenzen, d) Toluen [28] $\}$. 
It is more clear in Table 3, where the value of the effective mode area calculated at the wavelength $\lambda=1.55 \mu \mathrm{m}$ are listed. For example, for $\Lambda=2.0 \mu \mathrm{m}$ and $d / \Lambda=0.3$, the effective mode areas of PCF-N and PCF-T are $6.59148 \mu \mathrm{m}^{2}$ and $7.89287 \mu \mathrm{m}^{2}$ [28], respectively. That means PCF-N has an effective mode area with an amount of $1.30139 \mu \mathrm{m}^{2}$ smaller in comparison to that of PCF-T. As a result, in PCF-N, the light is strongly confined in the core, so this is expected to improve the efficiency of supercontinuum generation.

Table 3. The values of the effective mode area of PCF at the wavelength $\lambda=1.55 \mu \mathrm{m}$ for lattice constants $\Lambda=2.0 \mu \mathrm{m} ; \Lambda=2.5 \mu \mathrm{m}$ and filling factor $d / \Lambda$ varying from 0.3 to 0.8 .

\begin{tabular}{|c|c|c|c|c|c|}
\hline \multirow{2}{*}{$\lambda(\mu \mathrm{m})$} & \multirow{2}{*}{$d / \Lambda$} & \multicolumn{2}{|c|}{$\Lambda=2.0(\mu \mathrm{m})$} & \multicolumn{2}{|c|}{$\Lambda=2.5(\mu \mathrm{m})$} \\
\hline & & $\begin{array}{c}A_{\text {eff }} \\
\text { Nitrobenzen }\end{array}$ & $\begin{array}{c}\quad A_{\text {eff }} \\
\text { Toluen [28] }\end{array}$ & $\begin{array}{c}A_{e f f} \\
\text { Nitrobenzen }\end{array}$ & $\begin{array}{c}A_{\text {eff }} \\
\text { Toluen [28] }\end{array}$ \\
\hline \multirow{11}{*}{1.55} & 0.3 & 6.59148 & 7.89287 & 9.40071 & 10.74857 \\
\hline & 0.35 & 6.17038 & 7.21528 & 8.83289 & 9.96751 \\
\hline & 0.4 & 5.75024 & 6.57445 & 8.23517 & 9.16335 \\
\hline & 0.45 & 5.37657 & 6.06568 & 7.72592 & 8.61906 \\
\hline & 0.5 & 5.02807 & 5.59597 & 7.24536 & 7.92030 \\
\hline & 0.55 & 4.69506 & 5.17219 & 6.77437 & 7.35291 \\
\hline & 0.6 & 4.36883 & 4.77597 & 6.30456 & 6.85482 \\
\hline & 0.65 & 4.06776 & 4.42799 & 5.85389 & 6.34663 \\
\hline & 0.7 & 3.77444 & 4.08001 & 5.44266 & 5.86153 \\
\hline & 0.75 & 3.50436 & 3.77912 & 5.03024 & 5.42408 \\
\hline & 0.8 & 3.23427 & 3.47707 & 4.65846 & 4.98518 \\
\hline
\end{tabular}




\section{III.3. Chromatic dispersion}

The dispersion characteristics are simulated and presented in Fig. 5. The results show that the slope of dispersion curves is very large in the range of wavelength from $0.5 \mu \mathrm{m}$ to $0.9 \mu \mathrm{m}$, meanwhile, the dispersion is very flat and close to the zero-dispersion in the range of wavelength from $0.9 \mu \mathrm{m}$ to $2.0 \mu \mathrm{m}$. Moreover, the dispersion increases slightly as the filling factor $d / \Lambda$ increases. From all simulated cases, the dispersion curve of PCF-N for the case of $d / \Lambda=0.3$ is seen to be flattest and nearest to the zero-dispersion one. The obtained results are quite similar to that of PCF-T [28].
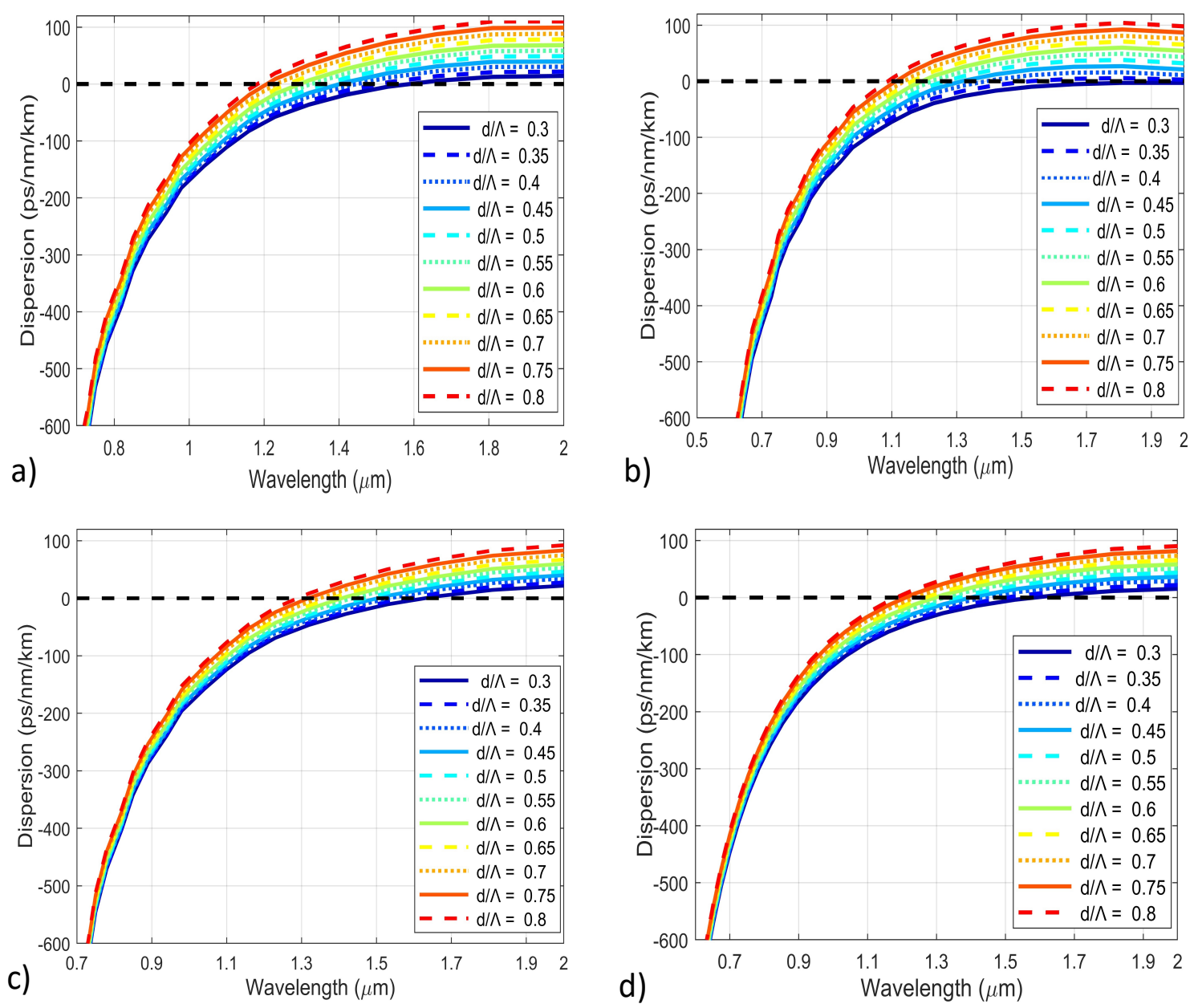

Fig. 5. D vs. $\lambda$ with $d / \Lambda$ varying from 0.3 to 0.8 and lattice constant $\Lambda=2.0 \mu \mathrm{m}\{\mathrm{a}$ ) Nitrobenzene, b) Toluene [28] $\}$ and $\Lambda=2.5 \mu \mathrm{m}\{\mathrm{c}$ ) Nitrobenzene, d) Toluene [28]\}.

In Table 4, there are values of chromatic dispersion of PCF-N and PCF-T [28] at $1.55 \mu \mathrm{m}$ wavelengths for all mentioned cases. It is clear that the value of dispersion in PFC-N is always smaller than that in PCF-T because the slope of the refractive index-wavelength characteristic of 
Nitrobenzene [5] is smaller than that of Toluene [37]. From Fig. 5, the value of the zero-dispersion wavelengths of PCF-N is found out in comparison to that of PCF-T [28] and listed in Table 4.

Table 4. The values of the chromatic dispersion of PCF at $1.55 \mu \mathrm{m}$ wavelengths for lattice constants $\Lambda=2.0 \mu \mathrm{m} ; \Lambda=2.5 \mu \mathrm{m}$ and filling factor $d / \Lambda$ that varies from 0.3 to 0.8 .

\begin{tabular}{|c|c|c|c|c|c|}
\hline \multirow{2}{*}{$\lambda(\mu \mathrm{m})$} & \multirow{2}{*}{$d / \Lambda$} & \multicolumn{2}{|c|}{$\Lambda=2.0(\mu \mathrm{m})$} & \multicolumn{2}{|c|}{$\Lambda=2.5(\mu \mathrm{m})$} \\
\hline & & $\begin{array}{c}\mathrm{D} \\
\text { Nitrobenzen }\end{array}$ & $\begin{array}{c}\text { D } \\
\text { Toluen [28] }\end{array}$ & $\begin{array}{c}\mathrm{D} \\
\text { Nitrobenzen }\end{array}$ & $\begin{array}{c}\text { D } \\
\text { Toluen [28] }\end{array}$ \\
\hline \multirow{11}{*}{1.55} & 0.3 & -8.98926 & -2.95775 & -8.15428 & -2.23706 \\
\hline & 0.35 & 4.94269 & 4.94935 & -3.36189 & 4.01279 \\
\hline & 0.4 & 11.54755 & 13.25179 & 2.06108 & 10.56447 \\
\hline & 0.45 & 21.15888 & 21.47950 & 6.97959 & 16.38819 \\
\hline & 0.5 & 29.26365 & 31.41146 & 12.27644 & 22.79784 \\
\hline & 0.55 & 37.56610 & 41.10117 & 17.69941 & 28.62156 \\
\hline & 0.6 & 46.28861 & 50.60247 & 24.03671 & 34.88916 \\
\hline & 0.65 & 55.40647 & 60.31910 & 30.37402 & 41.44084 \\
\hline & 0.7 & 64.91969 & 69.79348 & 37.35767 & 48.41865 \\
\hline & 0.75 & 75.44601 & 80.39833 & 45.09801 & 56.00014 \\
\hline & 0.8 & 86.59007 & 91.43384 & 53.50045 & 64.29184 \\
\hline
\end{tabular}


FEATURE PROPERTIES OF PHOTONIC CRYSTAL FIBER WITH HOLLOW CORE FILLED ...

Table 5. The value of the zero dispersion wavelength of PCF for lattice constants $\Lambda=$ $2.0 \mu \mathrm{m} ; \Lambda=2.5 \mu \mathrm{m}$ and filling factor $d / \Lambda$ that varies from 0.3 to 0.8 .

\begin{tabular}{|l|c|c|c|c|}
\hline \multirow{2}{*}{$d / \Lambda$} & \multicolumn{2}{|c|}{$\Lambda=2.0(\mu \mathrm{m})$} & \multicolumn{2}{c|}{$\Lambda=2.5(\mu \mathrm{m})$} \\
\cline { 2 - 5 } & $\begin{array}{c}\text { ZDWS } \\
\text { Nitrobenzen }\end{array}$ & $\begin{array}{c}\text { ZDWS } \\
\text { Toluen [28] }\end{array}$ & $\begin{array}{c}\text { ZDWS } \\
\text { Nitrobenzen } \\
\text { Toluen [28] }\end{array}$ \\
\hline 0.3 & 1.58664741 & No exist & 1.62722082 & 1.58410387 \\
\hline 0.35 & 1.50409702 & 1.50362011 & 1.58057710 & 1.50256610 \\
\hline 0.4 & 1.44384248 & 1.38821628 & 1.53151756 & 1.44046587 \\
\hline 0.45 & 1.39848922 & 1.31546402 & 1.49985186 & 1.39880211 \\
\hline 0.5 & 1.36181910 & 1.26882795 & 1.46725700 & 1.35888648 \\
\hline 0.55 & 1.32514197 & 1.22778822 & 1.43555414 & 1.32475633 \\
\hline 0.6 & 1.29573748 & 1.19571170 & 1.40325661 & 1.29574570 \\
\hline 0.65 & 1.26668632 & 1.16327120 & 1.37642253 & 1.26677669 \\
\hline 0.7 & 1.23638080 & 1.13715501 & 1.34746997 & 1.31669626 \\
\hline 0.8 & 1.18470507 & 1.08342116 & 1.29079134 & \\
\hline
\end{tabular}

From Table 5, we can see that the zero-dispersion wavelengths are in the near-infrared range and all zero-dispersion wavelengths in PCF-N are redshift in comparison to that of PCF-T. Moreover, there is an interesting point that in PCF-N with lattice constant $\Lambda=2.0 \mu \mathrm{m}$ and the filling factor $d / \Lambda=0.3$, the zero-dispersion exists at the wavelength of about $1.586 \mu \mathrm{m}$, but it does not exist in PCF-T. 


\section{III.4. Confinement Loss}

The confinement loss of PCF-N is simulated and listed in comparison to that of PCF-T in Fig. 6 and Table 6. The results show that the confinement loss decreases as lattice constant increases or filling factor decreases. It is especially important that with the same structure, the confinement loss of PCF-N is always smaller than that of PCF-T at the same wavelength. For example, with a structure of lattice constant $\Lambda=2.0 \mu \mathrm{m}$ and filling factor $d / \Lambda=0.3$, at the wavelength of $1.55 \mu \mathrm{m}$, the confinement loss of PCF-N is $0.2789046 \mathrm{~dB} / \mathrm{cm}$, which is smaller than the confinement loss of $0.4000211(\mathrm{~dB} / \mathrm{cm})$ of PCF-T [28]. This point can be seen as one of the advantages of PCF-N in comparison to that of PCF-T.
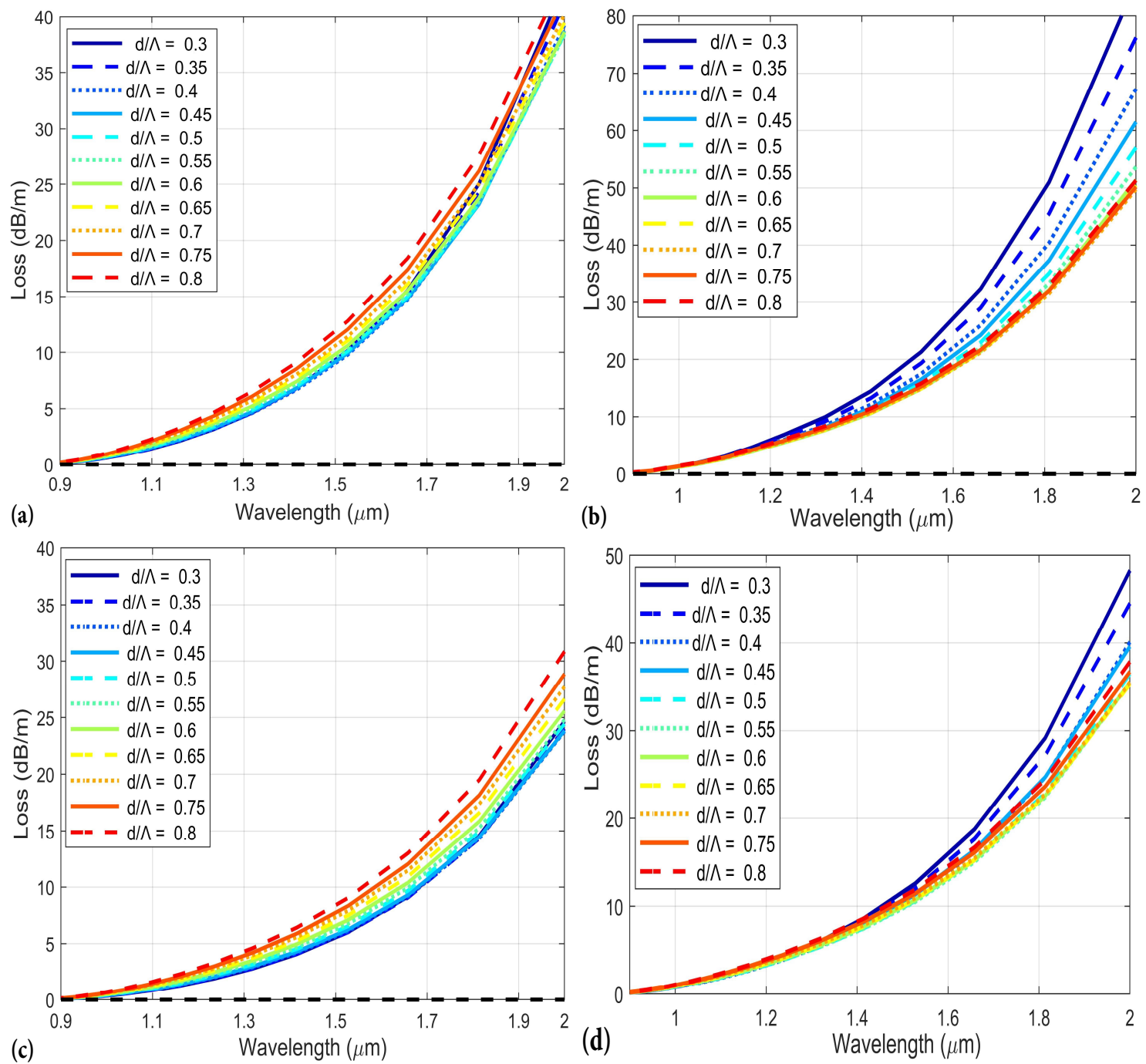

Fig. 6. $L_{c}$ vs. $\lambda$ with $d / \Lambda$ varying from 0.3 to 0.8 and lattice constant $\Lambda=2.0 \mu \mathrm{m}$ \{a) Nitrobenzene, b) Toluene [28] $\}$ and $\Lambda=2.5 \mu \mathrm{m}\{\mathrm{c}$ ) Nitrobenzene, d) Toluene [28] $\}$. 
Table 6. The value of the confinement loss of PCF for lattice constants $\Lambda=2.0 \mu \mathrm{m}$; $\Lambda=2.5 \mu \mathrm{m}$ and filling factor $d / \Lambda$ varying from 0.3 to 0.8 .

\begin{tabular}{|c|c|c|c|c|c|}
\hline \multirow{2}{*}{$\lambda(\mu \mathrm{m})$} & \multirow{2}{*}{$d / \Lambda$} & \multicolumn{2}{|c|}{$\Lambda=2.0(\mu \mathrm{m})$} & \multicolumn{2}{|c|}{$\Lambda=2.5(\mu \mathrm{m})$} \\
\hline & & $\begin{array}{c}L_{c}(\mathrm{~dB} / \mathrm{cm}) \\
\text { Nitrobenzene }\end{array}$ & $\begin{array}{c}L_{c}(\mathrm{~dB} / \mathrm{cm}) \\
\text { Toluene }[28]\end{array}$ & $\begin{array}{c}L_{c}(\mathrm{~dB} / \mathrm{cm}) \\
\text { Nitrobenzene }\end{array}$ & $\begin{array}{c}L_{c}(\mathrm{~dB} / \mathrm{cm}) \\
\text { Toluene [28] }\end{array}$ \\
\hline \multirow{11}{*}{1.55} & 0.3 & 0.2789046 & 0.4000211 & 0.2336577 & 0.3042101 \\
\hline & 0.35 & 0.2771894 & 0.3781645 & 0.2333847 & 0.2975773 \\
\hline & 0.4 & 0.2743669 & 0.3576502 & 0.2342890 & 0.2874381 \\
\hline & 0.45 & 0.2757010 & 0.3463501 & 0.2356881 & 0.2899125 \\
\hline & 0.5 & 0.2774888 & 0.3381698 & 0.238836 & 0.2820969 \\
\hline & 0.55 & 0.2797214 & 0.3321282 & 0.2410028 & 0.2807570 \\
\hline & 0.6 & 0.2825438 & 0.3282181 & 0.2452729 & 0.2827849 \\
\hline & 0.65 & 0.2871540 & 0.3282288 & 0.2489024 & 0.2835272 \\
\hline & 0.7 & 0.2910292 & 0.3278990 & 0.2533129 & 0.2850602 \\
\hline & 0.75 & 0.2977177 & 0.3317274 & 0.2577831 & 0.2904557 \\
\hline & 0.8 & 0.3057584 & 0.3375423 & 0.2653415 & 0.2950063 \\
\hline
\end{tabular}

\section{SUMMARY}

All principal properties of PCF-N have been investigated. To compare to characteristic quantities of PCF-T investigated in Ref. [28], we have paid attention to all of the structures with the lattice constants $\Lambda=2 \mu \mathrm{m}$ and $\Lambda=2.5 \mu \mathrm{m}$ and the filling factor $d / \Lambda$ varying from 0.3 to 0.8 . The obtained results show that there are some advantages in PCF-N as the effective index is higher, the effective area is smaller, the confident loss is lower, and the zero-dispersion wavelength redshift occurs in comparison to those of PCF-T. As shown in previous work [28], PCF-T can be used to generate the supercontinuum, so with the advantages mentioned above and the higher nonlinearity, we hope that the PCF-N could be used to generate the supercontinuum, whose broadband spectrum will be redshifted.

\section{ACKNOWLEDGMENT}

This research is funded by Vietnam National Foundation for Science and Technology Development (NAFOSTED) under grant number 103.03-2020.03. 


\section{REFERENCES}

[1] J. C. Knight, T. A. Birks, P. S. J. Russell, D. M. Atkin, Opt. Lett. 21 (1996) 1547.

[2] T. A. Birks, J. C. Knight, P. S. J. Russell, Opt. Lett. 22 (1997) 961.

[3] R. F. Cregan, B. J. Mangan, J. C. Knight, T. A. Birks, P. S. J. Russell, P. J. Roberts, D. C. Allan, Science 285 (1999) 1537.

[4] P. Russell, Science 299 (2003) 358.

[5] R. Buczyñski, Acta Physica Polonica A 106 (2004) 141.

[6] I. M. Nascimento, G. Chesini, M. Sousa, J. H. Osório, J. M. Baptista, C. M. B. Cordeiro, P. A. S. Jorge, Proc. SPIE 8794 (2013) 87941L.

[7] K. Barczak, Acta Physica Polonica A 122 (2012) 793.

[8] A. M. R. Pinto, M. Lopez-Amo, J. Sensors 2012 (2014) 598178.

[9] J. Knight, T. Birks, P. S. J. Russell, J. D. Sandro, J. Opt. Soc. Am. A 15 (1998) 748.

[10] F. E. Seraji, F. Asghari, Int. J. Opt. Photon. 3 (2009) 3.

[11] C. Martelli, J. Canning, M. Kristensen, N. Groothoff, Sensors 7 (2007) 2492.

[12] A. Ferrando, E. Silvestre, J. J. Miret, P. Andrés, M. V. Andrés, Opt. Photon. News 11 (2000) 32.

[13] N. A. Mortensen, Opt. Express 10 (2002) 341.

[14] N. Naddi, E. Mahammed, K. L. N. Ksihore, J. Electron. Commun. Engine. 12 (2017) 09.

[15] W. H. Reeves, J. Knight, P. S. J. Russell, P. Roberts, Opt. Express 10 (2002) 609.

[16] B. Dabas R. K. Sinha Opt. Commun 283 (2010) 1331.

[17] N. Karasawa, Appl. Opt. 51 (2012) 5259.

[18] S. Olyaee. F. Taghipour, J. Phys. Conf. Seri. 276 (2011) 012080.

[19] J. Pniewski, T. Stefaniuk, H. Le Van, V. Cao Long, L. Chu Van, R. Kasztelanic, G. Stêpniewski, A. Ramaniuk, M. Trippenbach, R. Buczyñski, Appl. Opt. 55 (2016) 5033.

[20] K. Dinh Xuan, L. Chu Van, V. Cao Long, Q. Ho Dinh, L. Van Mai, M. Trippenbach, R. Buczyñski, Opt. Quant. Electron. 49 (2017) 87.

[21] T. P. White, R. C. McPhedran, C. M. Sterke, L. C. Botton M. J. Steel, Opt. Lett. 26 (2001) 1660.

[22] K. Tajima, J. Zhou, K. Nakajima, K. Sato, J. Light wave Techno. 22 (2004) 7.

[23] D. Chen. L. Shen, Photon. Techno. Let. 19 (2007) 185.

[24] F. Koohi-Kamalia, M. Ebnali-Heidarib, M. K. Moravvej-Farshi, Int. J. Opt. Photon. 6 (2012) 83.

[25] H. Thenmozhi, M. Senthil, M. Rajan, V. Devika, D. Vigneswaran, N. Ayyanar, Int. J. Light Electron Opt. 145 (2017) 489.

[26] M. Ebnali-Heidari, F. Dehghan, H. Saghaei, F. Koohi-Kamali, M.K. Moravvej-Farshi, J. Modern Opt. 59 (2012) 1384.

[27] S. Liu, W. Gao, H. Li, Y. Dong, H. Zhang, Opt. Laser Techno. 64 (2014) 140.

[28] L. Chu Van, A. Anuszkiewicz, A. Ramaniuk, R. Kasztelanic, K. Xuan Dinh, M. Trippenbach, R. Buczyñski, J. Opt. 19 (2017) 125604.

[29] A. Bozolan, C. J. S. Matos, C. M. B. Cordeiro, E. M. Santos, J. Travers, Opt. Express 16 (2008) 9671.

[30] Z. Guo, J. Yuan, C. Yu, X. Sang, K. Wang, B. Yan, L. Li, S. Kang, X. Kang, Pro. Electromagnetics Research 48 (2016) 67.

[31] C. C. Wang, W. M. Li, N. Li, W. Q. Wang, Opt. Laser Techno. 88 (2017) 215.

[32] P. P. Ho, R. R. Alfano, Phys. Rev. A 20 (1979) 2170.

[33] S. Couris, Chem. Phys. Let. 369 (2003) 318.

[34] M. J. Soileau, E. W. V. Stryland, S. Guha, Mol. Cryst. liq. Cryst. 143 (1987) 139.

[35] K. Moutzouris, M. Papamichael, S. C. Betsis, I. Stavrakas, G. Hloupis, D. Triantis, Appl. Phys. B 116 (2014) 617.

[36] I. H. Malitson, J. Opt. Soc. Am. 55 (1965) 1205.

[37] S. Kedenburg, M. Vieweg, T. Gissibl, H. Giessen, Opt. Mater. Express 2 (2012) 1588. 